\title{
Renal papillary necrosis in a Paediatric Transplant Tourist - The challenge of providing continuity of care
}

\author{
Rosamund M. Akuse ${ }^{1}$, Mairo A. Bugaje ${ }^{l}$, Saad M.Yauba ${ }^{l}$, Nuhu D. Chom², \\ Ahmed U. Hamidu ${ }^{2}$ \\ ${ }^{I}$ Department of Paediatrics, Ahmadu Bello University Teaching Hospital, Zaria, Nigeria \\ ${ }^{2}$ Department of Radiology,Ahmadu Bello University Teaching Hospital, Zaria, Nigeria
}

\begin{abstract}
World Kidney Day 2012 focused on transplantation as a therapy for end-stage renal disease but facilities for paediatric transplantation in sub-Saharan Africa are limited. This causes parents of children needing transplantation to seek it elsewhere. Transplant centres must be aware of local issues which affect continuity of care of transplant tourists on return home as illustrated in this report. A 9 year old Nigerian had a live related renal transplant in India. Immunosuppressives were started immediately but they got exhausted after returning home. Financial constraints prevented his parents from obtaining more from India. They were reluctant to buy local drugs because of concerns about quality. Following counseling, he recommenced immunosuppressives. Five days later he developed haematuria. CT scans revealed renal papillary necrosis of the allograft. He improved with antibiotics and intravenous fluids. Clinic attendance and medication adherence were adversely affected by the parents' belief that transplantation was a cure. Twenty-one months posttransplant, allograft biopsy showed rejection. Because local issues affect care, collaboration between transplant centres, local physicians and international nephrology organizations are needed. Research into factors affecting outcome and strategies to overcome them is required. Meanwhile transplant centres should ensure patients return with six months' supply of immunosuppressives.
\end{abstract}

Key Words: Continuity of care, Paediatric renal transplant, Renal papillary necrosis, Transplant tourist

\section{Introduction}

During the 2012 World Kidney Day (a day set aside to raise awareness about the importance of kidneys), the success of of kidney transplantation as a therapy for end-stage renal disease (ESRD) was emphasized [1]. Though transplantation is expensive, and requires a high level of expertise, some authorities believe that it may be the only tenable long-term treatment option for ESRD even for resource constrained countries[1]. However at present, many sub-Saharan African countries have limited facilities for transplantation especially of children [2]. This causes parents of children needing transplantation to seek it elsewhere (a phenomenon known as transplant tourism [3, 4]. After transplantation, these transplant tourists are cared for in their own countries. Health workers of countries which transplant such patients must be aware of local issues that may affect their care. This report of a Nigerian child who developed renal papillary necrosis on return home after transplantation in another country illustrates this and offers suggestions about how to overcome some of the challenges of caring for such patients.

\section{Case Report}

A 9 year old Nigerian boy was referred to the Paediatric department of Ahmadu Bello University Teaching Hospital (ABUTH), Zaria with Acute Kidney Injury but investigations revealed he had End Stage Renal Disease. As none of the transplant centres in Nigeria at the time performed paediatric transplants, he was taken to India where he had a live related transplant with a kidney donated by his father. Post-operatively he was placed on triple immunosuppressive therapy (tacrolimus, mycophenolate sodium and prednisolone). His creatinine fell from a preoperative level of $990.1 \mathrm{umols} / 1$ to $61.9 \mathrm{umols} / 1$ and haemoglobin rose from $7.1 \mathrm{gm} \%$ to $13 \mathrm{gm} \%$. He returned to Nigeria but 40 days post-transplant, his stock of tacrolimus and mycophenolate sodium got exhausted. Financial constraints prevented his parents from obtaining more drugs from India and they were reluctant to buy locally available immunosuppresives because of concerns about drug quality. The patient reported to the paediatric nephrology clinic of ABUTH 45 days post-transplant. He had no complaints but both he and his parents were counseled about the need to continue to take all immunosuppresives. He restarted tacrolimus and mycophenolate sodium three days later with drugs obtained from reputable pharmaceutical companies. He presented on Day 57 post-transplant with a four day history of haematuria. Physical examination was normal. Abdominal ultrasound showed triangular hypoechogenecity in the papillary area of the allograft kidney suggestive of renal papillary necrosis which was confirmed by CT scans (Fig. 1). Apart from a slightly 
elevated urea level, other investigations were normal. His $\mathrm{Hb}$ electrophoretic pattern was AA and blood and urine cultures yielded no growth. There were no facilities to determine levels of immunosuppressives, presence of Cytomegalovirus or pneumocystis Giovanni and methylprednisolone was unavailable. It was decided to defer allograft biopsy unless his condition deteriorated. His oral immunosuppressives were continued and he was placed on intravenous fluids, antibiotics and antimalarials. He was discharged six days later with normal renal function.

He was followed up on outpatient basis with occasional consultations with his physicians in India but despite repeated counseling, clinic attendance was irregular. His parents appeared to believe renal transplantation was a cure. When evaluated in India 15 months post-transplant, his allograft was reported to be functioning well with creatinine levels of $88.4 \mathrm{umols} / \mathrm{l}$. Six months later he became anaemic $(\mathrm{Hb} 7.6 \mathrm{mg} / \mathrm{dl})$ with rising creatinine of 256umol/l. Screens for parasites, tuberculosis and, hepatitis B and C were negative. Allograft biopsy showed marked tubular atrophy but no active cellular rejection. A positive C4d stain of a sample sent to United Kingdom was suggestive of humoral rejection but could not be confirmed because the patient was unavailable to be tested for serum donor specific antibodies. His parents were counselled about various treatment options but stated they would take him back to India. Clinic attendance remains erratic and drug compliance suspect.

Fig. 1

\section{CT EXCRETORY UROGRAPHY SHOWING RENAL PAPILLARY NECROSIS}

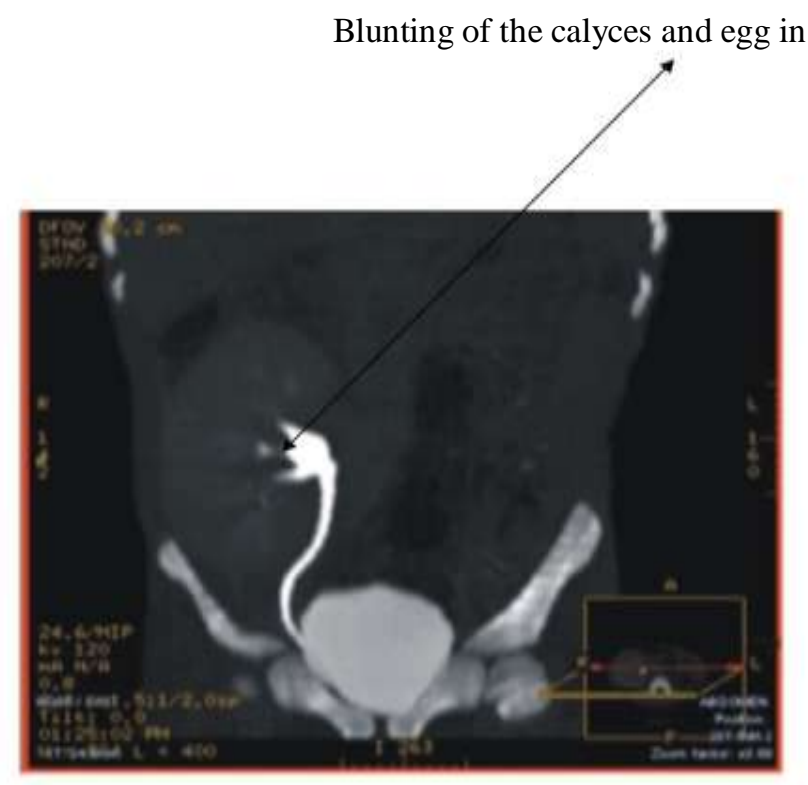

CT excretory urography showing enlarged transplanted kidney with typical egg in cup appearance of papillary necrosis (blunting of the calyces), involving the upper and lower moiety calyces.

\section{Discussion}

Economic constraints, limited diagnostic and therapeutic facilities affected continuity of care. So did concerns about the quality of locally available drugs and the parents' belief that transplantation was a cure.

Substandard and counterfeit medicines are found worldwide even in economically advanced countries but they are more of a problem in resource constrained countries [5]. Nigeria has had some success in battling this issue [6] and the parents' fears were probably not justified as there have been no reports of sale of substandard immunosuppressives. However the belief that transplantation is a cure for ESRD is quite common among the general public and makes patients and their relatives careless about follow up and medication adherence [7]. Significant non-adherence is estimated to cause rejection in $22 \%$ of renal transplant recipients [8] but it was difficult to determine whether non-adherence in this patient was significant. The development of Renal Papillary necrosis (RPN) suggests that it was. RPN refers to necrosis of the medulla of the kidney as a result of ischaemic insults. It is commonly associated with analgesic use, diabetes mellitus, urinary tract infection, sickle cell anaemia, and septicaemia -none of which were present in this patient [9]. RPN can also occur as a complication of transplant rejection [9,10]. Recognition of the condition is important because RPN can lead to infection, urinary obstruction, and renal failure or indicate rejection [9]. Without microscopic evidence, it cannot be categorically stated that rejection was the cause of this patient's RPN but the history of non-adherence and lack of evidence of other conditions usually associated with it makes it a possibility. 
Transplant tourism is increasing worldwide and so it is important that there should be close collaboration between transplant centres and physicians in patients' home countries whose knowledge of local situations is invaluable. For example local physicians would know where to source good quality drugs, and local beliefs and attitudes that might affect compliance. Centres which transplant tourists could provide continued support for their patients e.g. samples for investigations which are not readily available could be sent to them and the results communicated to physicians in the patient's home country. A small additional fee could be built into the cost of the transplant. This would improve continuity of care, increase allograft survival and thus encourage more referrals to such centres with resultant economic benefits. Data must be collected about issues which affect patient care and outcomesin various countries. This could be coordinated by international societies of Nephrology e.g. the International Society of Nephrology and Transplantation Society who have pledged to work to establish appropriate kidney programs in low income countries [1]. This should involve training of health workers and help in provision of less expensive generic immunosuppresives. Meanwhile it is recommended that transplant centres make it mandatory that patients return home with a six months' supply of immunosuppressives while nephrologists in resource constrained countries continue to work for improved facilities, subsidies for transplanted patients and development of local transplant programs.

\section{V. Conclusion}

International collaboration is needed to identify issues which affect continuity of care of transplant tourists and strategies developed to overcome them. The knowledge gained would surely benefit all transplant patients worldwide.

\section{References}

[1] Garcia GG, Harden PN, Chapman JR; World Kidney Day Steering Committee 2012. World Kidney Day 2012. The global role of kidney transplantation. Am J kidney Dis,59(3), 2012, 319-24

[2] Naicker S. Burden of end-stage renal disease in sub-Saharan Africa. Clin Nephrol ,Suppl 1; 74(S1), 2010, S13-16.

[3] Canales MT, Kasiske BL, Rosenberg ME. Transplant tourism: Outcomes of United States residents who undergo kidney transplantation overseas. Transplantation, 82, 2006, 1658-61.

[4] Ackoundou-N'Guessan C, Gnionsahe DA, Dekou AH, Tia WM, Guei CM, Moudachirou AM. Outcomes of renal patients from the Ivory Coast transplanted abroad: time for a local kidney transplantation program. Transplant Proc, 42,2010, 3517-20.

[5] World Health Organization. Substandard and counterfeit medicines. 2003 . Fact sheet $N^{\circ} 275$. www.who.int/mediacentre/factsheets/2003/fs275/en

[6] Nwosu U. Council Closes 200 Illegal Medicine Shops in Aba, Umuahia.4 Jul 2011 allafrica.com/stories/201107050853.html accessed 12.06.2012

[7] Obom-Egbulem K. Renal failure and the other side of kidney transplant. Nigeria Health Watch Journal. nigerianhealthjournal.com/?p=139 March 10, 2010

[8] Prendergast MB, Gaston RS. Optimizing medication adherence: an ongoing opportunity to improve outcomes after kidney transplantation. Clin J Am SocNephrol,5, 2010, 1305-1311. doi: 10.2215/CJN.07241009

[9] Powell C, Donohoe JM, Mydlo JH. Papillary Necrosis emedicine.medscape.com/article/439586. accessed 15.06.2012

[10] Kaude JV, Stone M, Fuller TJ, Cade R, Tarrant DG, Juncos LI. Papillary necrosis in kidney transplant patients.Radiology, 120, 1976, 69-74. 